\title{
Drought-mediated extinction of an arid-land amphibian: insights from a spatially explicit dynamic occupancy model
}

\author{
Erin R. Zylstra iD,${ }^{1,5,6}$ Don E. Swann, ${ }^{2}$ Blake R. Hossack, ${ }^{3}$ Erin Muths iD, 4 and Robert J. Steidl (iD) \\ ${ }^{1}$ School of Natural Resources and the Environment, University of Arizona, Tucson, Arizona 85721 USA \\ ${ }^{2}$ National Park Service, Saguaro National Park, Tucson, Arizona 85730 USA \\ ${ }^{3}$ U.S. Geological Survey, Northern Rocky Mountain Science Center, Missoula, Montana 59801 USA \\ ${ }^{4}$ U.S. Geological Survey, Fort Collins Science Center, Fort Collins, Colorado 80526 USA
}

Citation: Zylstra, E. R., D. E. Swann, B. R. Hossack, E. Muths, and R. J. Steidl. 2019. Drought-mediated extinction of an arid-land amphibian: insights from a spatially explicit dynamic occupancy model. Ecological Applications 29(3):e01859. 10.1002/eap.1859

\begin{abstract}
Understanding how natural and anthropogenic processes affect population dynamics of species with patchy distributions is critical to predicting their responses to environmental changes. Despite considerable evidence that demographic rates and dispersal patterns vary temporally in response to an array of biotic and abiotic processes, few applications of metapopulation theory have sought to explore factors that explain spatiotemporal variation in extinction or colonization rates. To facilitate exploring these factors, we extended a spatially explicit model of metapopulation dynamics to create a framework that requires only binary presence-absence data, makes few assumptions about the dispersal process, and accounts for imperfect detection. We apply this framework to $22 \mathrm{yr}$ of biannual survey data for lowland leopard frogs, Lithobates yavapaiensis, an amphibian that inhabits arid stream systems in the southwestern United States and northern Mexico. Our results highlight the importance of accounting for factors that govern temporal variation in transition probabilities, as both extinction and colonization rates varied with hydrologic conditions. Specifically, local extinctions were more frequent during drought periods, particularly at sites without reliable surface water. Colonization rates increased when larval and dispersal periods were wetter than normal, which increased the probability that potential emigrants metamorphosed and reached neighboring sites. Extirpation of frogs from all sites in one watershed during a period of severe drought demonstrated the influence of site-level features, as frogs persisted only in areas where most sites held water consistently and where the amount of sediment deposited from high-elevation wildfires was low. Application of our model provided novel insights into how climaterelated processes affected the distribution and population dynamics of an arid-land amphibian. The approach we describe has application to a wide array of species that inhabit patchy environments, can improve our understanding of factors that govern metapopulation dynamics, and can inform strategies for conservation of imperiled species.
\end{abstract}

Key words: Bayesian state-space model; climate; colonization; extinction; Lithobates yavapaiensis; lowland leopard frog; metapopulation dynamics; sedimentation; stream network.

\section{INTRODUCTION}

Ongoing and anticipated changes in climate, disturbance regimes, and land use are expected to influence the distributions of many species (Parmesan 2006, Ehrlén and Morris 2015). Effects of climate change might be particularly important, as distributional limits often have a direct physiological basis defined by a species' tolerance to climatic conditions (Gaston 2003).

Manuscript received 31 May 2018; revised 28 November 2018; accepted 21 December 2018. Corresponding Editor: Trenton W. J. Garner.

${ }^{5}$ Present address: Department of Integrative Biology, Michigan State University, 288 Farm Lane, East Lansing, Michigan 48824 USA.

${ }^{6}$ E-mail: ezylstra@email.arizona.edu
Changes in climate also might induce distributional shifts indirectly by altering distributions of predators and competitors and the quantity and quality of habitat available to species (Gaston 2003). Numerous studies have evaluated whether recent, rapid changes in climate have contracted or expanded the limits of species' distributions (Parmesan et al. 1999, Thomas and Lennon 1999, Parmesan 2006, Chen et al. 2011), but climate impacts may not be limited to range margins, especially if habitat for a species is discontinuous (Stewart et al. 2017). Identifying processes associated with changes in distributions of species that inhabit patchy environments can be especially challenging, particularly in dynamic systems (Hodgson et al. 2009, Miller et al. 2012). If these environments are surveyed consistently for long periods, however, extirpation and colonization events 
can be linked more directly to climate, disturbances, or other temporal processes through a metapopulation framework (Yackulic et al. 2015). This information can then be used to predict species responses to future environmental changes, which provides a foundation to inform conservation strategies for imperiled species that depend on patchy resources in dynamic environments.

Approaches for exploring dynamics of metapopulations have evolved considerably since Levins (1969) introduced the first deterministic, nonspatial models. Most contemporary approaches treat site occupancy as a stochastic process, where the current occupancy state of a site depends on occupancy at the previous time step and extinction and colonization (i.e., transition) probabilities. Approaches that are spatially explicit better reflect metapopulation theory by allowing transition probabilities to vary with the spatial arrangement of sites and dispersal capabilities of the target species through an incidence function (Hanski et al. 1996, Hanski 1999, Risk et al. 2011) or by integrating other measures of connectivity (Franken and Hik 2004, Heard et al. 2013, Sutherland et al. 2014). A number of recent spatial models incorporate a state-space approach to overcome the limitations of imperfect surveys (Bled et al. 2011, Yackulic et al. 2012, Heard et al. 2013, Sutherland et al. 2014, Chandler et al. 2015, Broms et al. 2016). Most frequently, these spatial models have been used to (1) estimate site-specific rates of extinction, colonization, or turnover, (2) assess metapopulation viability, and (3) evaluate whether observed distributional dynamics of species match theoretical expectations. Rarely, however, have studies explored temporal variation in extinction and colonization probabilities, despite substantial evidence that demographic rates and dispersal behaviors vary temporally in response to an array of biotic and abiotic processes (e.g., O'Brien et al. 2003, Robinson et al. 2007, Knowlton and Graham 2010). Even when long-term data are available, temporal effects are seldom explored because existing models (1) assume that dynamic parameters remain constant over time or vary only with patch area or degree of connectivity (Risk et al. 2011, Chandler et al. 2015), (2) require supplementary demographic data (Harrison et al. 2011, Heard et al. 2013, Sutherland et al. 2014), or (3) make assumptions about dispersal processes that may not hold for all species (Bled et al. 2011, Yackulic et al. 2012, Eaton et al. 2014, Broms et al. 2016). Given ongoing and rapid changes in climate and land use, however, accounting for temporal variation in dynamic parameters can help to refine models of metapopulation dynamics and increase the reliability of predictions about future system states.

Recently, Chandler et al. (2015) developed a spatially explicit occupancy model to describe metapopulation dynamics of a desert-breeding amphibian following its reintroduction. This model allowed for inferences about metapopulation extinction risk and connectivity while accounting for imperfect surveys, but assumed timeinvariant rates of local extinction and colonization. Here, we extend this model to account for uncertainty in initial occupancy states, and more importantly, to allow extinction and colonization probabilities to vary over both space and time as a function of environmental covariates. We apply the model to $22 \mathrm{yr}$ of biannual survey data for lowland leopard frogs (Lithobates yavapaiensis), a species of conservation concern in the southwestern United States and northern Mexico (Sredl et al. 1997). In southeastern Arizona, lowland leopard frogs primarily inhabit stream reaches in arid mountain canyons, environments that are rare on the landscape, highly dynamic, and likely to change in response to anticipated shifts in climate and other anthropogenic threats (Grimm and Fisher 1992, Sredl 2005, Wallace et al. 2010, Jaeger et al. 2014). Although abundance of lowland leopard frogs fluctuates in response to hydrologic conditions (Zylstra et al. 2015), there is growing evidence of systematic declines and extirpations in populations across this region (Sredl et al. 1997, Witte et al. 2008, Savage et al. 2011). Identifying factors associated with these declines is a conservation priority and can provide insight into the dynamics of this and other sensitive species that depend on surface water in arid mountain systems.

The objectives of our paper are three-fold. First, we present a hierarchical, spatially explicit framework for metapopulations to explore spatial and temporal variation in transition probabilities. This framework requires only binary data and relies on few assumptions about the dispersal process. Second, we illustrate this approach using long-term survey data for lowland leopard frogs to evaluate how extinction and colonization rates varied over time. This case study highlights the value of biannual surveys that allowed us to assess the relative influence of multiple threats that might vary seasonally. Third, we use simulations to forecast metapopulation dynamics of lowland leopard frogs under a range of climate scenarios, demonstrating how the framework can be used to assess probability of metapopulation persistence over the long term. We also provide computer code needed to run the model, with notes about potential modifications or extensions to facilitate application to other species and ecosystems.

\section{Methods}

\section{Study area}

We studied population dynamics of lowland leopard frogs in the Madrean Sky Island region of southeastern Arizona, where isolated mountain ranges are separated by large expanses of desert and semi-desert grasslands. We surveyed frogs in the Rincon Mountains, much of which lies within the boundaries of Saguaro National Park, east of Tucson, Arizona. The Rincon Mountains range from $900 \mathrm{~m}$ to 2,640 m elevation and encompass at least four distinct vegetation communities that range from Sonoran desert scrub to mixed-conifer forests (Brown 1982, Bowers and McLaughlin 1987). The area 
is bisected by a ridge formation that runs southwest to northeast with deeply incised canyons forming the headwaters of two watersheds, one north and one south of the ridge (Valentine-Darby et al. 2017). The landscape outside of these canyons is arid, particularly below $1,500 \mathrm{~m}$ elevation, where there is little to no surface water. Flow in most stream reaches is intermittent, with seasonal variation reflecting a bimodal pattern of annual precipitation (300-700 mm/yr, depending on elevation; Brown 1982, Bowers and McLaughlin 1987). In winter (December-April), pools are often connected by continuous flow produced by widespread cool-season rains whereas in late spring (May-June) and fall (OctoberNovember), channels between pools dry frequently (Grimm and Fisher 1992, Wallace et al. 2010). During monsoon season (July-September), localized, highintensity storms can trigger sporadic flash floods. Because lowland leopard frogs in the Sky Island region inhabit low-order streams below approximately 1,400 m elevation, we restricted surveys to canyon reaches at middle elevations $(870-1,370 \mathrm{~m})$, where pools are associated frequently with bedrock outcroppings. Most pools are $<2 \mathrm{~m}$ deep with surface areas $3-12 \mathrm{~m}^{2}$ and have limited soil-bank development (Wallace et al. 2010).

\section{Field surveys}

We surveyed leopard frogs in eight canyons, four in the northern watershed and four in the southern watershed (Fig. 1). Canyons contained 213 pools that were likely to contain water much of the year and provide habitat for frogs. Between May 1996 and June 2017, we surveyed streams when they typically were not flowing, in both spring (16 May-15 July) and fall (1 October-30 November), which we defined as sampling periods ( $n=43$; Fig. 2). Each stream reach was surveyed 0-13 times per sampling period by one to four observers, at least one of which had surveyed these canyons for
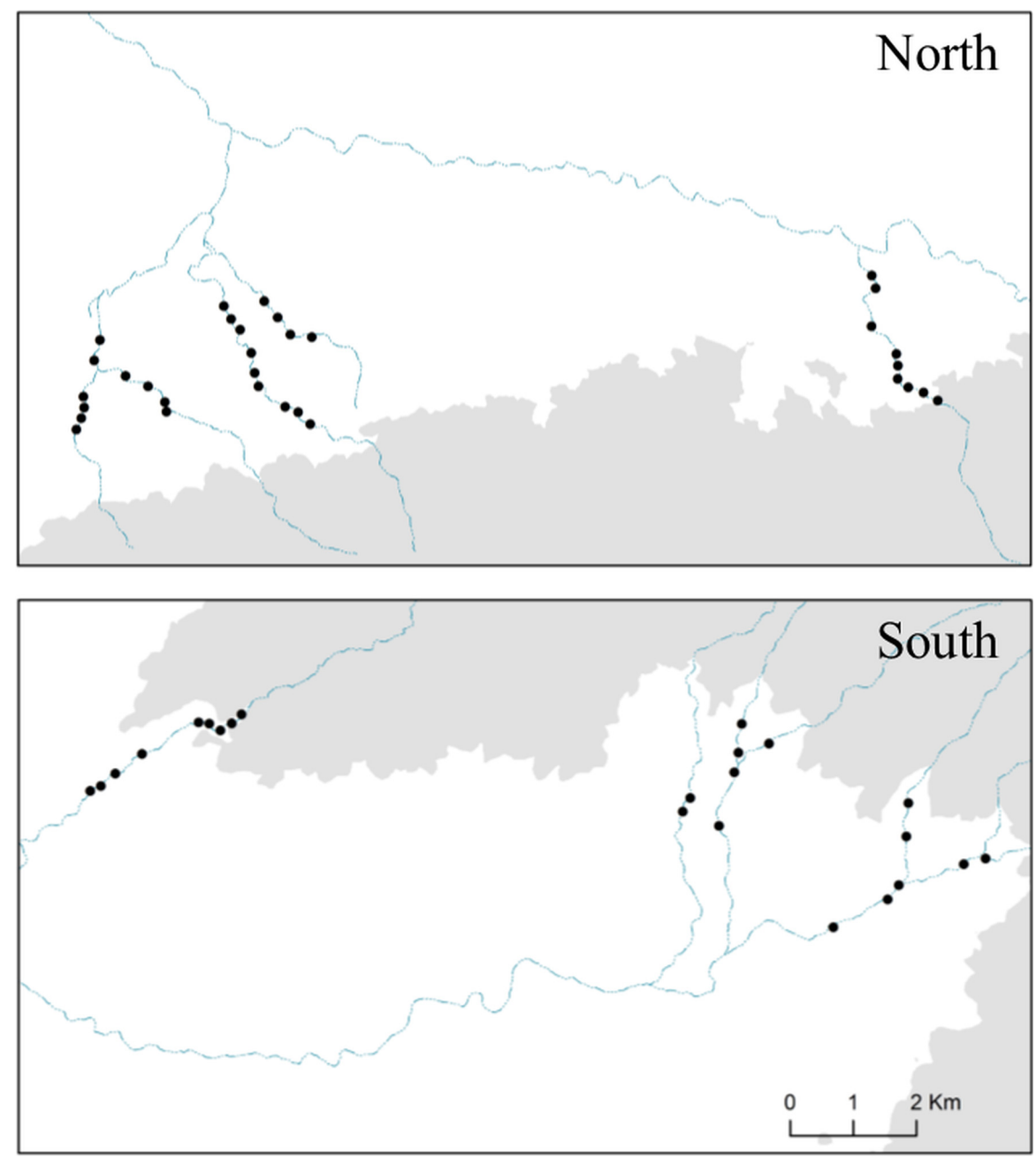

FIG. 1. Maps of pool complexes surveyed for lowland leopard frogs in two watersheds (North, South) in the Rincon Mountains. Each black dot represents the approximate midpoint of a pool complex. Areas above 1,370 m elevation are shaded gray. 


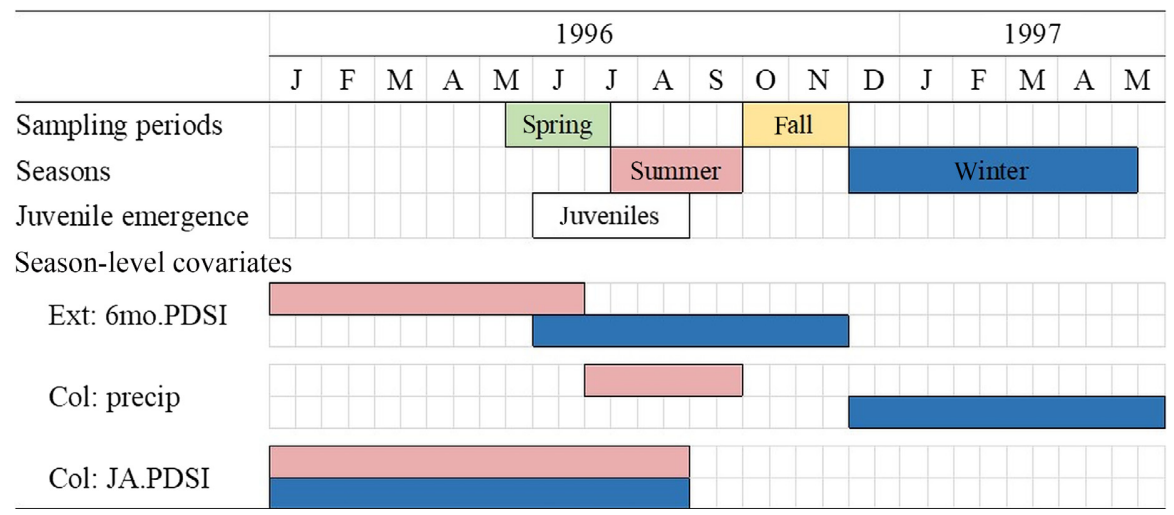

FIG. 2. A timeline illustrating relationships among sampling periods, seasons, and periods when we measured covariates. For simplicity, we illustrate these relationships from January 1996 to May 1997, a period that encompasses only the first 2 of 43 sampling periods in the 22-yr study. Each box represents an approximate 15-d period (i.e., the first or second half of each month). We surveyed for post-metamorphic leopard frogs during spring and fall sampling periods (shaded green and yellow, respectively), and assumed colonization and extinction events occurred during the intervening summer and winter seasons (red and blue, respectively). We related extinction probabilities (Ext) in summer and winter to Palmer Drought Severity Index averaged over the preceding sixmonth period (6mo.PDSI; shaded to correspond with associated season). We related colonization probabilities (Col) during summer and winter to current precipitation (precip) and to drought indices averaged over the eight-month period leading up to and including when the most recent cohort of newly transformed juveniles emerged (JA.PDSI).

leopard frogs previously. Observers followed standard protocols for diurnal visual encounter surveys (VES; Zylstra et al. 2015), and at each pool recorded whether water was present and whether they observed $\geq 1$ post-metamorphic (i.e., juvenile or adult) lowland leopard frog.

Although surveyors recorded observations of leopard frogs at each pool, many pools were in close proximity and did not function as independent habitat patches. Therefore, we aggregated data among pools $<150 \mathrm{~m}$ apart (stream distance) and refer to these aggregations as pool complexes. We delineated pool complexes based on the expectation that when streams were not flowing (i.e., during spring and fall sampling periods) frogs were unlikely to move among complexes. This resulted in 55 pool complexes, 32 in the northern watershed and 23 in the southern watershed, which encompassed most, if not all, of the high quality habitat available to leopard frogs in the eight canyons. In most instances, all pools in a complex were surveyed in a single day. Occasionally, however, surveys of large complexes (eight or more pools) spanned two days within a five-day period; we considered these as one survey in our analyses.

\section{Occupancy model}

We extended the spatially explicit dynamic occupancy model of Chandler et al. (2015) to allow extinction and colonization probabilities to vary over space and time as a function of environmental covariates. We used a statespace formulation, with variation in survey data decomposed into a state or ecological process (here, occupancy of frogs over time and space) and an observation process (Royle and Kéry 2007). Survey data consisted of $y_{i, k, t}=1$ if observers detected $\geq 1$ leopard frog or $y_{i, k, t}=0$ if observers detected no frogs at pool complex $i(i=1, \ldots, 55$ sites) on survey $k(k=1, \ldots, 13)$ in sampling period $t$ $(t=1, \ldots, 43)$. We assumed closure within sampling periods and allowed occupancy to vary between spring and fall sampling periods (i.e., during summer and winter seasons; Fig. 2). We considered the ecological process to be Markovian, with occupancy after the first sampling period conditional on occupancy in the previous sampling period. Our model consisted of two dynamic parameters, the probability of colonization if the site was unoccupied previously $(\gamma)$ and probability of persistence $(\varphi)$ if the site was occupied previously. Unlike the model of Chandler et al. (2015), we modeled the true occupancy state of site $i$ in the first sampling period, $z_{i, 1}$, as a Bernoulli random variable with probability of initial occupancy, $\psi_{i, 1}: z_{i, 1} \sim \operatorname{Bernoulli}\left(\psi_{i, 1}\right)$. We modeled occupancy in subsequent sampling periods as:

$$
z_{i, t+1} \mid z_{i, t} \sim \operatorname{Bernoulli}\left(\gamma_{i, t}\left(1-z_{i, t}\right)+\phi_{i, t} z_{i, t}\right)
$$

where $\gamma_{i, t}$ is the probability that an unoccupied site was colonized between time $t$ and $t+1$ and $\phi_{i, t}$ is the probability an occupied site remained occupied between $t$ and $t+1$.

Consistent with metapopulation theory (Hanski 1999), we allowed colonization and persistence probabilities to vary with proximity to other occupied sites. We began by modeling pairwise colonization probabilities, defined as the probability that site $i$ was colonized by at least one individual from site $j$ between sampling period $t$ and $t+1, \delta_{i, j, t}$ :

$$
\delta_{i, j, t}=\delta_{B, i, t} \exp \left(-d_{i, j}^{2} /\left(2 \theta^{2}\right)\right) z_{j, t}
$$

where $\delta_{B, i, t}$ is the "baseline" colonization probability for sites coincident to site $i, d_{i, j}$ is the distance between sites, 
and $\theta$ is the scale parameter in a Gaussian dispersal kernel governing how colonization probability decreases with distance (Chandler et al. 2015). Most metapopulation models use Euclidian distances to approximate the minimum distance individuals must travel to colonize a neighboring site. If movements of individuals between sites are unlikely to follow straight-line paths, however, other distance measures may be more appropriate. Similar to many dendritic stream networks, we expected aridity, landscape structure, and topography to constrain movements of lowland leopard frogs among sites. Specifically, we assumed that high-elevation ridges and ephemeral flow of valley-bottom streams would prevent frogs from moving between watersheds, and therefore delineated two metapopulations based on watershed boundaries. For sites in the same canyon that were flowconnected (sensu Peterson et al. 2013), we used stream distances instead of Euclidean distances, as this likely reflected how frogs move within canyons. For sites in the same watershed that were not flow-connected, we used minimum out-of-stream distances after restricting movement paths to areas below $1,370 \mathrm{~m}$, which is the approximate upper elevational limit for the species in the region (Wallace et al. 2010). Most out-of-stream distances were considerably greater than stream distances between sites that were flow connected (Fig. 1). We explored alternative approaches for computing pairwise distances (e.g., stream distances only, out-of-stream distances only), but found that inferences about metapopulation dynamics were similar regardless of how we specified distances.

After defining pairwise colonization probabilities, we calculated the cumulative probability that site $i$ was colonized between sampling period $t$ and $t+1$ as

$$
\gamma_{i, t}=1-\left\{\prod_{j=1}^{\mathrm{N}_{i}} 1-\delta_{i, j, t}\right\}
$$

where $\mathrm{N}_{i}$ is the number of other sites in the same watershed as site $i$. We allowed for the possibility that sites could go extinct and be recolonized between consecutive sampling periods (i.e., a pseudo-rescue effect; Hanski 1999, Sutherland et al. 2014, Chandler et al. 2015): $\phi_{i, t}=1-\varepsilon_{i, t}\left(1-\gamma_{i, t}\right)$, where $\varepsilon_{i, t}$ is the probability that site $i$ goes extinct between sampling period $t$ and $t+1$.

Finally, we modeled the observation process separately from ecological processes because observers may fail to detect frogs when a site is truly occupied (Royle and Kéry 2007, Zylstra et al. 2015). Because we assumed changes in occupancy would occur only between sampling periods, multiple surveys of a site within a sampling period allowed us to estimate detection probability $(p)$ or the probability of detecting $\geq 1$ post-metamorphic frogs if the site is occupied. We assumed a Bernoulli distribution for detection-nondetection data: $y_{i, k, t} \sim$ $\operatorname{Bernoulli}\left(z_{i, t} \times p_{i, k, t}\right)$.

We modeled extinction and baseline colonization probabilities $\left(\varepsilon_{i, t}\right.$ and $\left.\delta_{B, i, t}\right)$, as well as initial occupancy and detection probabilities $\left(\psi_{i}\right.$ and $\left.p_{i, k, t}\right)$, as logit-linear functions of site-, season- and survey-level covariates. We used the same general structure for each linear model, where probability on the logit scale was modeled as a function of an intercept $(\alpha)$ and a set of fixed effects ( $\boldsymbol{\beta})$ describing the relationship between covariates $(\mathbf{X})$ and probability of extinction, colonization, initial occupancy, or detection probability (e.g., $\operatorname{logit}\left(\psi_{i}\right)=\alpha_{\psi}+$ $\left.\boldsymbol{X}_{i} \boldsymbol{\beta}_{\psi}\right)$. We standardized all continuous covariates prior to analysis. In the following sections, we describe relevant covariates and specify the linear model for each parameter.

\section{Environmental covariates}

Site-level covariates. - For each complex (i.e., site), we determined the number of pools (npools) and mean elevation (elev) across pools. We estimated the area of each basin that drained into the lowest-elevation pool in each complex (area) using hydrology tools in ArcGIS 10.1 (ESRI, Redlands, California, USA). Reliability of surface water in canyons is governed by several factors, including pool depth and groundwater connectivity (Valentine-Darby et al. 2017). Because these measures were not available for all pool complexes, we used information on water availability collected during VES surveys to create an index of water reliability for each site across the 22-yr study period. We determined the number of sampling periods each pool was surveyed at least once and calculated the proportion of those sampling periods during which the pool did not go dry. We then used the maximum value among pools within each complex as an index of surface-water reliability (reliability). This resulted in potential values of surface-water reliability that ranged from 0 (all pools in a complex went dry during every sampling period the complex was surveyed) to 1 (at least one pool in a complex always held water).

Season-level covariates. -We identified a number of time-varying factors with potential to explain changes in site occupancy during summer and winter seasons. Wildfire and subsequent erosion can fill pools with sediment, decreasing their capacity to hold water for months to decades after a fire, which can influence colonization and extinction rates (Parker 2006). We created a discrete index of sediment levels in each of eight canyons over time (sediment) based on repeated measurements of sediment volume from 24 pools ( $0-7$ pools/canyon), data collected during VES surveys, and descriptions of sediment levels in one canyon from a study of wildfire in the Rincon Mountains (Parker 2006). For each summer and winter season, we assigned all complexes within a canyon the same sediment value. We classified sediment levels as low (sediment $=0$ ) when either mean sediment volume for measured pools was $<25 \%$ of pool volume, or, for those canyons where sediment volume was not quantified, $<20 \%$ of the watershed had burned in the preceding $10 \mathrm{yr}$ (Parker 2006). We classified sediment levels as moderate (sediment $=1$ ) when mean sediment 
volume of pools was approximately $25-50 \%$ and high (sediment $=2$ ) when mean sediment volume was $\geq 50 \%$.

We expected that colonization and extinction probabilities might vary over time in response to weather and its effects on surface-water availability. Specifically, we hypothesized that drought could increase extinction probabilities by decreasing the amount of surface water available for frogs, particularly at the beginning of summer and winter seasons. We estimated the effect of drought for each canyon using downscaled, monthly measures of Palmer Drought Severity Index (PDSI) between 1996 and 2017 (Abatzoglou et al. 2017; data available online). ${ }^{7}$ For each summer (July-September) and winter (DecemberMay), we calculated mean PDSI during the preceding sixmonth period (January-June and June-November, respectively; 6mo.PDSI; Fig. 2) because this measure was associated with surface-water availability at the end of spring and fall sampling periods (Appendix S1).

We expected that weather might affect colonization probabilities in two ways: (1) drought could reduce the number of juveniles available to colonize other sites by reducing the number of tadpoles that reach metamorphosis and (2) decreases in precipitation during summer or winter could increase desiccation-related mortality rates of individuals moving between sites. To explore the first possibility, we calculated mean PDSI over an eightmonth period (January-August) leading up to and including when the most recent cohort of juveniles emerged (hereafter, the larval period; JA.PDSI; Fig. 2). To explore the second possibility, we obtained downscaled, monthly estimates of precipitation and 30-yr normals (1981-2010) for each canyon from the PRISM Climate Group (data available online). ${ }^{8}$ For each summer and winter, we calculated the percentage of precipitation normals from July-September and December-May, respectively (precip; Fig. 2).

Survey-level covariates. - Because we expected surfacewater availability to affect frog activity patterns and detection probability during VES surveys (Zylstra et al. 2015), we calculated the proportion of pools in each complex with water during each survey (water). We also created a binary variable to differentiate surveys that were led by observers with less experience (approximately one to nine previous surveys; obs) from those led by individuals with extensive survey experience $(\geq 10$ previous surveys).

\section{Model implementation and inferences}

We modeled variation in the probability of occupancy among sites in spring of 1996 as a function of basin area, number of pools in each complex, and mean elevation. We included a quadratic term for elevation to allow for nonlinear relationships between initial occupancy and elevation:

\footnotetext{
${ }^{7}$ https://wrcc.dri.edu/wwdt

${ }^{8} \mathrm{http}: / /$ prism.oregonstate.edu
}

$$
\begin{aligned}
\operatorname{logit}\left(\psi_{i, 1}\right)= & \alpha_{\psi}+\beta_{\psi \text {.area }}\left(\text { area }_{i}\right)+\beta_{\psi \text {.pools }}\left(\text { npools }_{i}\right) \\
& +\beta_{\psi \text {.elev }}\left(\text { elev }_{i}\right)+\beta_{\psi \text {.elev } 2}\left(\text { elev }_{i}^{2}\right)
\end{aligned}
$$

where $\alpha_{\psi}$ is the mean probability of initial occupancy across all sites on the logit scale. We allowed extinction and colonization probabilities to vary between summer and winter seasons, and to vary with basin area, surfacewater reliability, and sediment levels. In addition, we allowed extinction probabilities to vary as a function of drought over the preceding six-month period, and included an interaction term to allow the effect of drought to differ between summer and winter:

$$
\begin{aligned}
\operatorname{logit}\left(\varepsilon_{i, t}\right)= & \alpha_{\varepsilon}+\beta_{\varepsilon . \text { area }}\left(\text { area }_{i}\right)+\beta_{\varepsilon . \text { rel }}\left(\text { reliability }_{i}\right) \\
& +\beta_{\varepsilon . \text { sed }}\left(\text { sediment }_{i, t}\right)+\beta_{\varepsilon . \text { win }}\left(\text { winter }_{t}\right) \\
& +\beta_{\varepsilon . d r}\left(6 \text { mo.PDSI }_{i, t}\right) \\
& +\beta_{\varepsilon . \text { windr }}\left(\text { winter }_{t} \times 6 \text { mo.PDSI }_{i, t}\right)
\end{aligned}
$$

where $\alpha_{\varepsilon}$ is the probability of extinction in summer for sites with low sediment levels on the logit scale. We modeled baseline colonization probabilities as a function of drought during the preceding larval period and precipitation during summer and winter. Similar to the model for extinction, we included interactions between hydrologic variables and season:

$$
\begin{aligned}
\operatorname{logit}\left(\delta_{B, i, t}\right)= & \alpha_{\delta}+\beta_{\delta . \text { area }}\left(\text { area }_{i}\right)+\beta_{\delta . \text { rel }}\left(\text { reliability }_{i}\right) \\
& +\beta_{\delta . \text { sed }}\left(\text { sediment }_{i, t}\right)+\beta_{\delta \text {.win }}\left(\text { winter }_{t}\right) \\
& +\beta_{\delta . d r}\left(\text { JA.PDSI }_{i, t}\right) \\
& +\beta_{\delta . \text { windr }}\left(\text { winter }_{t} \times J A . P D S I_{i, t}\right) \\
& +\beta_{\delta . \text { precip }}\left(\text { precip }_{i, t}\right) \\
& +\beta_{\delta \text {.winprecip }}\left(\text { winter }_{t} \times \text { precip }_{i, t}\right)
\end{aligned}
$$

where $\alpha_{\delta}$ is baseline colonization probability in summer at sites with low sediment levels on the logit scale. For site-level covariates, we assumed baseline colonization probabilities varied with characteristics of the recipient site (i). Alternatively, we might have modeled $\delta_{B, i, j, t}$ instead of $\delta_{B, i, t}$ and incorporated covariates to represent differences in habitat characteristics between sites $i$ and $j$, similar to other gradient-based approaches that have been used for birds (Broms et al. 2016). We opted for the simpler approach given that lowland leopard frogs have limited dispersal capabilities and low rates of post-metamorphic survival (Zylstra et al. 2019). Finally, we allowed detection probability to vary between spring and fall sampling periods, vary with observer experience, and vary with availability of surface water:

$$
\begin{aligned}
\operatorname{logit}\left(p_{i, k, t}\right)= & \alpha_{p}+\beta_{p . \text { fall }}\left(\text { fall }_{t}\right)+\beta_{p . \text { obs }}\left(\text { obs }_{i, k, t}\right) \\
& +\beta_{p \text { water }}\left(\text { water }_{i, k, t}\right)+\beta_{p . \text { water } 2}\left(\text { water }_{i, k, t}^{2}\right)
\end{aligned}
$$

where $\alpha_{p}$ is mean detection probability of experienced observers in spring on the logit scale. 
We specified vague priors for all parameters. We specified a logistic prior for intercepts in regression models, $\alpha \sim \operatorname{Logistic}(\mu=0, \sigma=1)$, which implied a Uniform $(0$, 1) prior for $\psi, \varepsilon, \delta$, and $p$ when all covariates were equal to zero (Northrup and Gerber 2018). We specified Nor$\operatorname{mal}\left(\mu=0, \sigma^{2}=10\right)$ priors for all regression coefficients describing effects of covariates on initial occupancy, colonization, extinction, and detection probabilities on the logit scale. Finally, we specified a Uniform prior for theta, the scale parameter describing the rate of decay in colonization probability with distance: $\theta \sim \operatorname{Uniform}(0$, $15)$. We fit our model in JAGS executed from $\mathrm{R}$ using the package jagsUI (Kellner 2015, R Core Team 2016); we provide our code in Data S1. We ran three Markov chains initiated at random values for 85,000 iterations. We discarded the first 5,000 iterations as adaptation and burn-in and retained 1 of every 40 iterations thereafter to summarize the posterior distribution. We assessed convergence by inspecting trace plots and checking that Gelman-Rubin $\hat{R}$ statistics were $<1.1$ (Gelman and Rubin 1992).

We assessed the extent to which each covariate explained variation in colonization, extinction, initial occupancy, or detection probability, conditional on other covariates in the model, by evaluating whether $95 \%$ credible intervals (CI) excluded zero and by calculating a posterior probability (PP) value, defined as the proportion of samples from the posterior distribution that were $>0$ if the mean of the posterior was positive or $<0$ if the mean was negative. For example, if the mean of the posterior distribution for $\beta_{\psi \text {.area }}$ was positive, but $20 \%$ of posterior samples were negative ( $\mathrm{PP}=0.80$ ), we would conclude there was only weak evidence that probability of initial occupancy was associated positively with basin area. We generated posterior distributions for the proportion of sites occupied in each watershed during each of the 43 sampling periods (1996-2017) and used a Bayesian beta regression model (Ferrari and Cribari-Neto 2004) to assess the relationship between these posterior occupancy probabilities and drought indices averaged over the preceding 12 months (spring, June-May; fall, October-September). Unless noted otherwise, we used $95 \%$ credible intervals to characterize uncertainty of estimates based on posterior distributions.

\section{Forecasting effects of climate on metapopulation persistence}

We used simulations to forecast effects of potential changes in climate on persistence of leopard frog metapopulations in arid mountain canyons. We assessed the probability that a metapopulation would persist over a 30-yr period under three climate scenarios: (1) neutral conditions, with monthly PDSI $=0$ and precipitation equal to 30-yr normals; (2) persistent mild drought, with PDSI $=-1.5$ and precipitation in summer and winter equal to $75 \%$ of normals; and (3) periodic extreme drought, with PDSI $=-4.5$ and precipitation equal to $50 \%$ of normals for three years followed by seven years of mild drought conditions, repeated three times. We based these scenarios on climate projections for the southwestern United States (Seager et al. 2007, Cook et al. 2015) as well as values from the Rincon Mountains during our 22-yr study. We simulated occupancy dynamics for four hypothetical metapopulations, each consisting of 48 sites distributed evenly among eight canyons, to evaluate the relative importance of water reliability

TABLE 1. Summaries of environmental covariates used to explain variation in initial occupancy, extinction, colonization, and detection probability of lowland leopard frogs surveyed in pool complexes in two watersheds (South, North) in the Rincon Mountains, Arizona, USA between 1996 and 2017.

\begin{tabular}{|c|c|c|c|c|c|}
\hline \multirow[b]{2}{*}{ Covariate } & \multirow[b]{2}{*}{ Label } & \multicolumn{2}{|c|}{ South $(n=23)$} & \multicolumn{2}{|c|}{ North $(n=32)$} \\
\hline & & Mean & Range & Mean & Range \\
\hline \multicolumn{6}{|l|}{ Site level } \\
\hline No. pools & npools & 4.0 & 1,13 & 3.8 & 1,16 \\
\hline Elevation (m) & elev & 1137 & 962,1357 & 1056 & 873,1359 \\
\hline Basin area $\left(\mathrm{km}^{2}\right)$ & area & 11.6 & $3.9,32.9$ & 7.9 & $1.9,18.1$ \\
\hline Water reliability & reliability & 0.85 & $0.19,1.00$ & 0.63 & $0.10,1.00$ \\
\hline \multicolumn{6}{|l|}{ Season level } \\
\hline Sediment levels & sediment & 0.54 & 0,1 & 0.88 & 0,2 \\
\hline Drought (prior 6 months) & 6mo.PDSI & -1.9 & $-5.4,4.5$ & -1.6 & $-4.6,4.7$ \\
\hline Drought (larval period) & JA.PDSI & -2.0 & $-5.5,4.4$ & -1.7 & $-4.6,4.6$ \\
\hline Precipitation ( $\%$ normals) & precip & 88 & 16,203 & 89 & 17,206 \\
\hline \multicolumn{6}{|l|}{ Survey level } \\
\hline Surface-water availability & water & 0.84 & $0.00,1.00$ & 0.66 & $0.00,1.00$ \\
\hline
\end{tabular}

Notes: For season-level covariates, we provide the mean value across all summer and winter seasons and for survey-level covariates we provide the mean value across all surveys in each spring or fall sampling period. We used a discrete index to classify sediment levels (0, low; 1, moderate; 2, high), Palmer Drought Severity Index to characterize drought (negative values indicate drought; positive values indicate wetter than normal conditions), and continuous indices that ranged from 0 to 1 to characterize water reliability and surface-water availability during each survey. 
and distance between sites. Specifically, we established metapopulations in areas where water reliability was either high $(30 \%$ of sites with permanent water, mean reliability $=0.85)$ or low $(15 \%$ of sites permanent, mean reliability $=0.60$ ) and distances between sites were either short (distances between adjacent canyons ranged from 1 to $5 \mathrm{~km}$, mean distance between all pairs of canyons $=8.6 \mathrm{~km}$ ) or long (range of distances $=2$ $8 \mathrm{~km}$, mean $=13.6 \mathrm{~km}$ ). For each metapopulation, we fixed initial occupancy equal to 0.50 , sediment levels as low, and basin area of each site equal to the observed mean. We assumed the effects of drought and precipitation on extinction and colonization probabilities were identical to those we observed between 1996 and 2017. We predicted occupancy of sites in each metapopulation over time, with associated uncertainty, by combining posterior draws from extinction and colonization parameters based on observed data with projected PDSI and precipitation values under each climate scenario. For each metapopulation and climate scenario, we calculated the proportion of 48 sites that were occupied in each spring and fall sampling period and computed probability of metapopulation extinction as the proportion of Monte Carlo Markov chain (MCMC) iterations in which no sites were occupied after $30 \mathrm{yr}$. We expected our estimates of extinction probabilities to be conservative, as 48 sites represents a large metapopulation relative to those we studied and others in this region.

\section{RESUlts \\ Field surveys}

We surveyed 55 pool complexes distributed across eight canyons, with each complex containing between 1 and 16 pools $($ mean $=3.9)$. Basin area of complexes averaged $9.4 \mathrm{~km}^{2}$, with those in the southern watershed averaging $3.7 \mathrm{~km}^{2}$ larger than complexes in the northern watershed (Table 1). In $75 \%$ of complexes $(n=41)$, at least one pool held water during $\geq 50 \%$ of all sampling periods (reliability $\geq 0.50) ; 25 \%$ of complexes $(n=14)$ held water permanently (reliability $=1.0$ ). Water was less reliable in the northern than southern watershed, as $37.5 \%$ of northern pool complexes $(n=12)$ and only $8.7 \%$ of southern complexes $(n=2)$ were dry during $>50 \%$ of sampling periods (reliability $<0.50$; Table 1 ). Sediment reached high levels (mean sediment volume $\geq$ $50 \%$ ) in two of eight canyons, both in the northern watershed (Table 1). In these two canyons, sediment levels peaked approximately $1.5 \mathrm{yr}$ after wildfires in 1999 and 2003 and remained high for 5-7 yr.

On average, we surveyed each pool complex in 26.0 \pm 0.87 (mean \pm SE) of 43 sampling periods (range $=12-39$ sampling periods/complex) and visited complexes an average of $1.7 \pm 0.05$ times during each of those sampling periods (range $=1-13$ surveys/sampling period/complex). More than $82 \%$ of surveys were led by observers with extensive survey experience. Most complexes $(80 \%, n=44)$ were visited more than once within multiple sampling periods, which provided information about detection probability, and there was a slight increase in the mean number of surveys per sampling period per complex over time (slope $=0.02$ surveys/sampling period/complex, 95\% CI $=0.00-0.04$ ). There was more surface water available for frogs during fall (mean proportion of pools in a complex with water $=0.84)$ than spring $(0.65)$, although drought conditions prevailed throughout much of the study. Both mean PDSI and precipitation were well below normal (PDSI $=-1.7$; monthly precipitation $=84 \%$ of $30-\mathrm{yr}$ normals), with exceptional drought conditions observed in most canyons in 2013 and 2014 (minimum monthly

TABLE 2. Posterior means, standard deviations (SD), and 95\% credible intervals (CI) for parameters from a dynamic occupancy model for lowland leopard frogs in southern Arizona, USA.

\begin{tabular}{|c|c|c|c|c|}
\hline Parameter & Mean & $\mathrm{SD}$ & $95 \% \mathrm{CI}$ & PP \\
\hline \multicolumn{5}{|c|}{ Initial occupancy } \\
\hline$\alpha_{\psi}$ & 0.15 & 1.31 & $-2.26,2.96$ & \\
\hline$\beta_{\psi \text {.area }}$ & 2.68 & 1.67 & $0.37,6.72$ & 0.9 \\
\hline$\beta_{\psi \text {.pools }}$ & 3.09 & 2.18 & $-0.11,8.12$ & 0.97 \\
\hline$\beta_{\psi \text {.elev }}$ & 0.21 & 1.85 & $-3.67,3.64$ & 0.5 \\
\hline$\beta_{\psi \text {.elev2 }}$ & -0.33 & 2.28 & $-4.62,4.46$ & 0.58 \\
\hline \multicolumn{5}{|l|}{ Extinction } \\
\hline$\alpha_{\varepsilon}$ & -0.13 & 0.71 & $-1.35,1.47$ & \\
\hline$\beta_{\varepsilon \text {.area }}$ & 0.16 & 0.68 & $-0.76,1.99$ & 0.50 \\
\hline$\beta_{\varepsilon . \text { rel }}$ & -1.85 & 0.45 & $-2.78,-1.05$ & 1.00 \\
\hline$\beta_{\varepsilon \text {.sed }}$ & -0.24 & 0.44 & $-1.15,0.60$ & 0.70 \\
\hline$\beta_{\varepsilon \text {.win }}$ & -1.92 & 0.91 & $-3.89,-0.34$ & 0.99 \\
\hline$\beta_{\varepsilon . \mathrm{dr}}$ & -0.44 & 0.48 & $-1.39,0.49$ & 0.82 \\
\hline$\beta_{\varepsilon \text {.windr }}$ & -1.17 & 0.86 & $-3.01,0.41$ & 0.92 \\
\hline \multicolumn{5}{|l|}{ Colonization } \\
\hline$\alpha_{\delta}$ & -2.47 & 0.55 & $-3.58,-1.42$ & \\
\hline$\beta_{\delta \text {.area }}$ & 0.87 & 0.40 & $0.27,1.85$ & 1.00 \\
\hline$\beta_{\delta \text {.rel }}$ & 0.11 & 0.19 & $-0.26,0.49$ & 0.71 \\
\hline$\beta_{\delta \text {.sed }}$ & -0.72 & 0.33 & $-1.36,-0.05$ & 0.98 \\
\hline$\beta_{\delta \text {.win }}$ & -1.11 & 0.92 & $-3.10,0.52$ & 0.90 \\
\hline$\beta_{\delta . d r}$ & 0.39 & 0.21 & $-0.02,0.82$ & 0.97 \\
\hline$\beta_{\delta \text {.windr }}$ & -1.13 & 0.98 & $-3.23,0.49$ & 0.88 \\
\hline$\beta_{\delta \text {.precip }}$ & 1.12 & 0.44 & $0.28,2.03$ & 1.00 \\
\hline$\beta_{\delta \text {.winprecip }}$ & -1.11 & 0.53 & $-2.17,-0.12$ & 0.99 \\
\hline$\theta$ & 1.90 & 0.82 & $0.73,3.55$ & \\
\hline \multicolumn{5}{|l|}{ Detection } \\
\hline$\alpha_{p}$ & 1.30 & 0.15 & $1.01,1.61$ & \\
\hline$\beta_{\text {p.fall }}$ & 1.23 & 0.21 & $0.83,1.66$ & 1.00 \\
\hline$\beta_{\text {p.obs }}$ & -0.68 & 0.23 & $-1.13,-0.23$ & 1.00 \\
\hline$\beta_{\text {p.water }}$ & -0.14 & 0.15 & $-0.44,0.15$ & 0.8 \\
\hline$\beta_{\text {p.water2 }}$ & -1.03 & 0.16 & $-1.35,-0.72$ & 1.00 \\
\hline
\end{tabular}

Notes: For regression coefficients $(\beta)$, we report the proportion of samples from the posterior distribution $>0$ if the mean is positive or $<0$ if the mean is negative (PP). $\alpha$ represents the intercept term from a logistic regression model. $\psi, \varepsilon, \delta$, and $p$ indicate whether the parameter is associated with initial occupancy, extinction, colonization, and detection, respectively. $\theta$ represents the scale parameter in a Gaussian dispersal kernel. See equations $2,4,5,6$, and 7 for more details. 
PDSI ranged from -4.8 to -6.2$)$. Observers were more likely to detect frogs in fall (318 of 944 surveys, 34\%) than in spring (411 of 1410 surveys, 29\%). Post-metamorphic leopard frogs were detected at least once in $71 \%$ of pool complexes $(n=39)$.

\section{Occupancy}

Across all sites, probability of initial occupancy averaged 0.52 and was higher for complexes with more pools and larger basin areas (Table 2). From 1996 to 2008, the first $13 \mathrm{yr}$ of the study, the proportion of sites occupied in each watershed fluctuated between 0.20 and 0.61 , and peaked in fall 2008 (Fig. 3). Shortly thereafter, occupancy declined precipitously in the northern watershed, with no observations of lowland leopard frogs after spring 2015 (Fig. 3). In contrast, occupancy in the southern watershed continued to fluctuate between 0.38 and 0.61 for the remainder of the study.

In general, local populations were more dynamic during summer than winter, with both extinction and colonization probabilities lower during winter, except during severe droughts (Table 2; Figs. 4 and 5). Local populations were more likely to go extinct (most probabilities $>0.2$ ) at sites where surface water was less reliable (reliability $\leq 0.25$ ) than sites where at least one pool held water permanently (probabilities $<0.2$, except during extreme drought; Fig. 4). Extinction probabilities did not vary with sediment levels or basin area after accounting for season, water reliability, and drought $(\mathrm{PP}=0.70$ and 0.50 , respectively; Table 2$)$.

During winter, sites were unlikely to be colonized (probabilities $<0.12$ ) regardless of hydrologic conditions or site characteristics (Fig. 5). During summer, sites were more likely to be colonized when the preceding larval period (January-August) was wetter than normal and when precipitation during summer monsoons was above average (Fig. 5). Colonization probabilities also varied as a function of site characteristics and distance.
Specifically, the odds that frogs colonized an adjacent site were 4.2 times higher $(95 \% \mathrm{CI}=1.1-15.2)$ when sediment levels at the recipient site were low rather than high, regardless of sediment levels at the site of origin. Frogs were also more likely to colonize sites in close proximity $(<2 \mathrm{~km})$ to their natal site (Appendix S2). Sites were 2.2 times $(95 \% \mathrm{CI}=1.1-8.3)$ more likely to be colonized by frogs from a site $150 \mathrm{~m}$ away compared to a site $1.5 \mathrm{~km}$ away, assuming the recipient site had little to no sediment.

Effects of drought on occupancy differed between watersheds. Between 1996 and 2014, estimates of the proportion of sites occupied were associated positively with PDSI (i.e., lower occupancy during drought) in the northern watershed (slope on the logit scale $=0.21,95 \%$ $\mathrm{CI}=0.14-0.29$ ) but not the southern watershed (slope $=0.04,95 \% \mathrm{CI}=-0.03$ to 0.11 ; Fig. 6).

Observers were likely to detect leopard frogs at occupied complexes (mean survey-specific $p=0.82$ ), especially when the site was surveyed more than once during a sampling period (mean probability that experienced observers would detect leopard frogs at least once after two surveys of a complex was >0.95). Detection probability was higher in fall than spring and peaked at intermediate levels of surface-water availability (proportion of pools with water $=0.70 ;$ Appendix S3: Fig. S1).

\section{Forecasts}

In the absence of drought, metapopulations of lowland leopard frogs composed of 48 sites are unlikely to go extinct within $30 \mathrm{yr}$ (extinction probabilities $<0.03$ ). When mild or extreme droughts occur, however, some metapopulations are vulnerable to extinction, particularly if few sites have pools that hold water reliably (extinction probabilities $=0.11-0.41 ;$ Fig. 7a, c). When extreme droughts occur at least once per decade, all metapopulations are vulnerable to extinction within

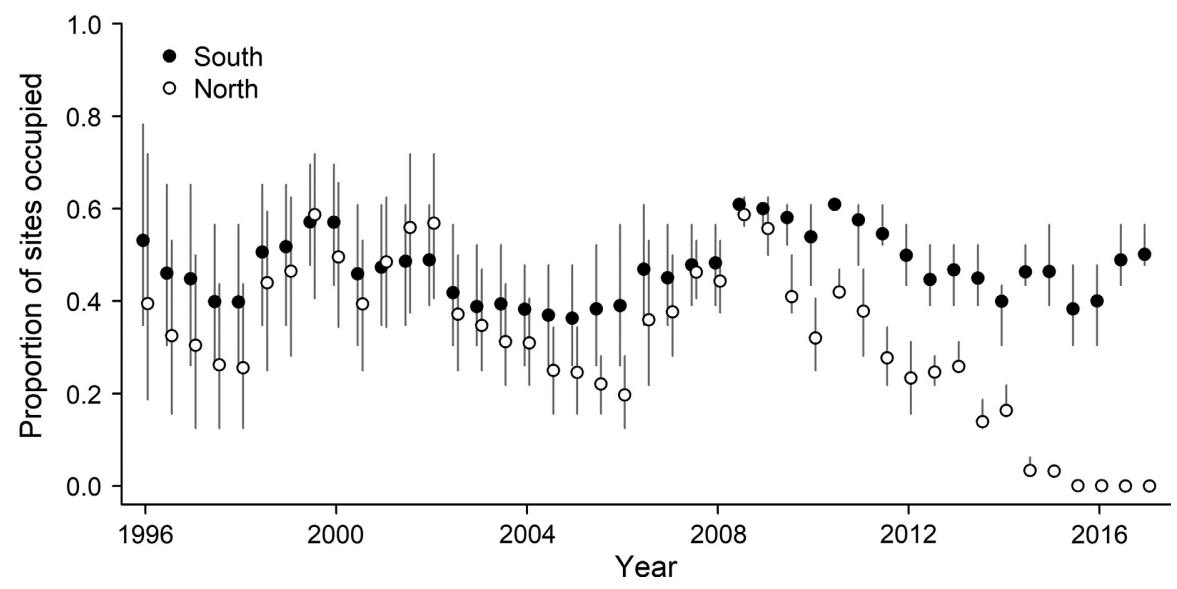

FIG. 3. Estimated proportion of sites (with $95 \%$ CI) occupied by lowland leopard frogs in two watersheds in the Rincon Mountains, Arizona, USA in spring (16 May-15 July) and fall (1 October-30 November) sampling periods between 1996 and 2017. 

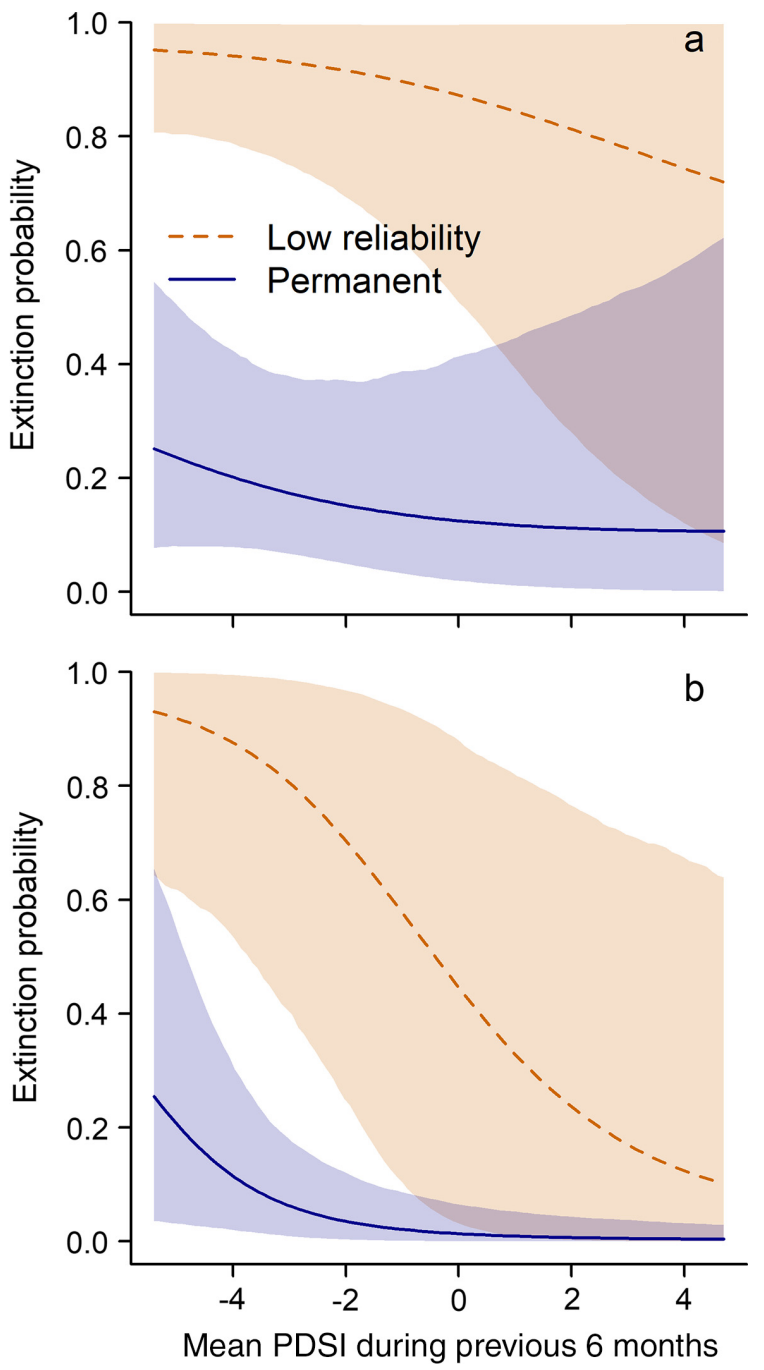

FIG. 4. Extinction probabilities for populations of lowland leopard frogs in (a) summer (16 July-30 September) and (b) winter (1 December-15 May) as a function of mean Palmer Drought Severity Index (PDSI) during the previous six months and water reliability (permanent sites had $\geq 1$ pools that never went dry; low-reliability sites went dry during $75 \%$ of spring and fall sampling periods). Negative PDSI values indicate drought; positive PDSI values indicate wetter than normal conditions. To predict extinction probabilities, we assumed sediment levels were low and basin area was equal to the mean across all pool complexes.

$30 \mathrm{yr}$, regardless of water reliability and distances between sites. In the absence of wildfires, the spatial arrangement of sites has less of an effect on persistence than does water reliability (Fig. 7), although sites are less likely to be recolonized following extreme drought if distances between adjacent canyons are large $(2-8 \mathrm{~km})$.

\section{DisCUSSION}

We extended an existing model of metapopulation dynamics by incorporating a flexible approach to account for temporal variation in extinction and colonization probabilities when surveys are imperfect and when demography and dispersal data are limited or absent. Our extension provides an approach to explore mechanisms that underlie changes in the distribution of a species over time. For example, it is possible to assess the roles and relative importance of time-varying biotic (e.g., distributions of competitors, predators, or diseases) and abiotic factors (e.g., land use, climate) in describing changes in species distributions, and to use these insights to inform conservation strategies. Although previous studies have suggested that these extensions were possible, few applications have incorporated time-varying covariates in models of extinction and colonization, particularly in a spatially explicit framework that accounts for imperfect detection.

\section{Effects of drought on metapopulation dynamics}

Changes in climate, especially increases in drought frequency and severity, have been implicated in declines of many amphibians in the western United States and around the world (Daszak et al. 2005, Scheele et al. 2012, Hossack et al. 2013a). These changes have altered demographic rates (e.g., Reading 2007, Cayuela et al. 2016), shifted phenology of life-history events (e.g., Todd et al. 2011, Benard 2015), and reduced the quantity and quality of aquatic environments on which many amphibians depend (McMenamin et al. 2008, Werner et al. 2009, Pilliod et al. 2015). By allowing dynamic parameters to vary as a function of time-varying covariates, we were able to demonstrate that for lowland leopard frogs, both extinction and colonization processes were affected by drought-mediated factors, specifically reductions in surface water in arid mountain canyons.

Changes in occupancy or transition probabilities of amphibians that are active during only part of the year in temperate environments have been linked to variation in hydrologic conditions through data from annual surveys (Werner et al. 2009, Ray et al. 2016). Data from 22 yr of biannual surveys allowed us to explore seasonal variation in extinction and colonization processes for a species that is active year-round (Sredl 2005). Periods of severe drought decreased the amount of surface water available to post-metamorphic frogs in early summer or winter (Appendix S1), which increased extinction probabilities. In summer, colonization rates reflected both the number of potential emigrants and hydrologic conditions that affected the ability of emigrants to reach new sites. The number of emigrants arriving at a site is often assumed to scale with the area of neighboring occupied sites (Hanski 1999), but for many aquatic-breeding amphibians, recruitment fluctuates in response to precipitation and hydroperiod, such that temporal variation is likely more influential than patch area or other sitelevel characteristics (Pechmann et al. 1991, Daszak et al. 2005). For lowland leopard frogs, drought conditions during larval periods (January-August) increased the 

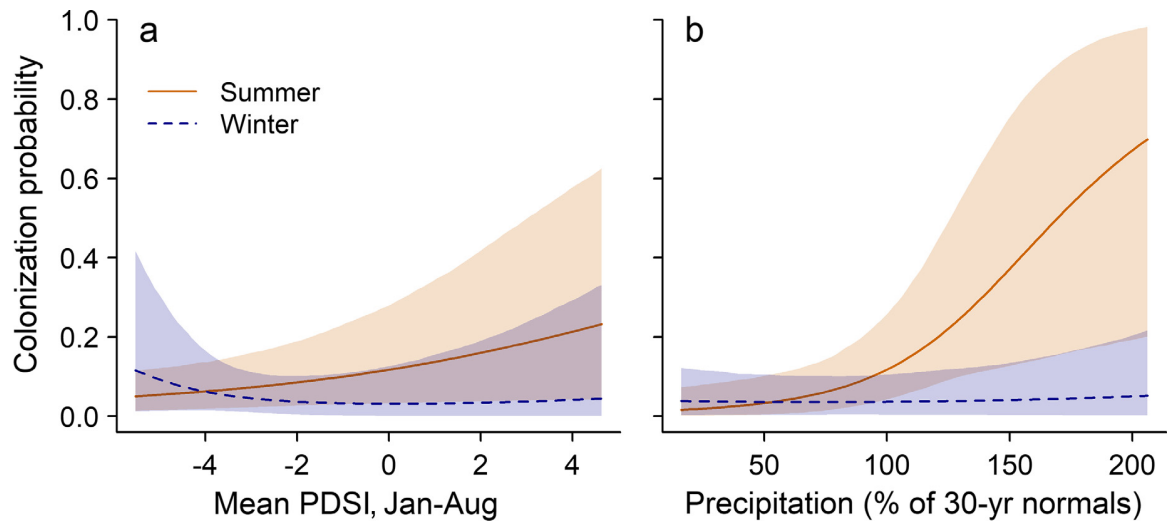

FIG. 5. Baseline colonization probabilities for populations of lowland leopard frogs in summer and winter as a function of (a) mean Palmer Drought Severity Index (PDSI) during the previous larval period (Jan-Aug) and (b) precipitation during current summer and winter seasons. Negative PDSI values indicate drought; positive PDSI values indicate wetter than normal conditions. To predict colonization probabilities as a function of drought, we fixed basin area and water reliability equal to their means across all pool complexes, sediment levels as low, and precipitation to its mean across all pool complexes and seasons. We similarly fixed basin area, reliability, sediment, and PDSI values to their means when predicting colonization probabilities as a function of precipitation.

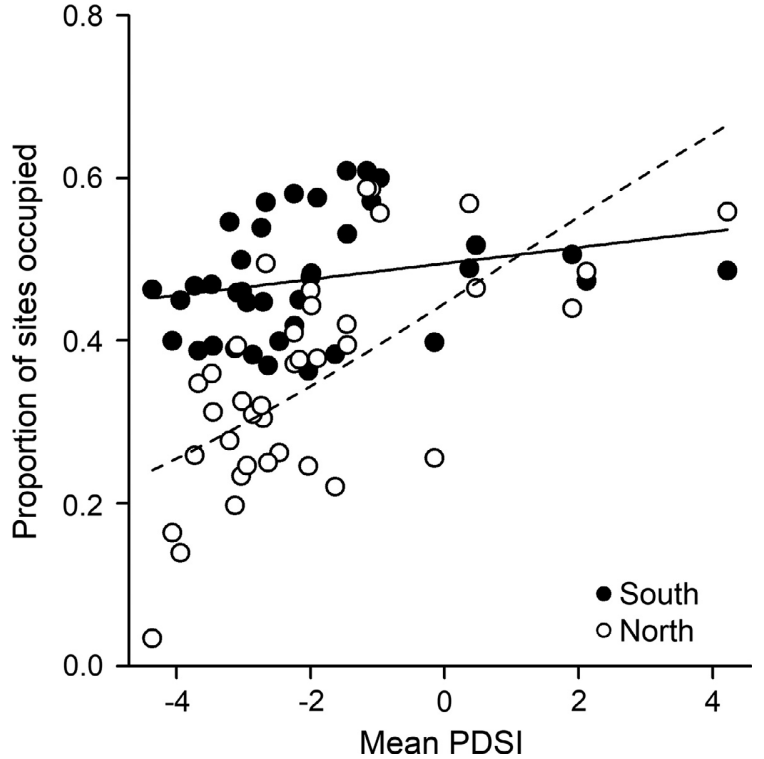

FIG. 6. Seasonal estimates of the proportion of sites occupied by lowland leopard frogs in two watersheds in the Rincon Mountains, Arizona, USA, 1996-2014, as a function of Palmer Drought Severity Index (PDSI) averaged over the preceding 12 months. Proportion of sites occupied was positively associated with PDSI in the northern watershed (dashed line; slope on logit scale $=0.21,95 \% \mathrm{CI}=0.14-0.29$ ), but not the southern watershed (solid line; slope $=0.04,95 \% \mathrm{CI}=-0.03-0.11$ ).

probability of recruitment failure, which decreased colonization rates the following summer. When recruitment was successful, however, individuals that metamorphosed were more likely to colonize neighboring pool complexes when monsoon rainfall was above average. Like cane toads (Rhinella marina), which reduce the frequency or spatial extent of movements during drought (Schwarzkopf and Alford 2002, Tingley and Shine
2011), lowland leopard frogs might have been less likely to emigrate from natal pools during dry summers, reducing colonization rates. Moreover, because rates of evaporative water loss are high in Lithobates spp. (Spotila and Berman 1976), low colonization rates during dry summers might have resulted from increased mortality of emigrants rather than, or in addition to, decreased probabilities of emigration. In winter, colonization rates of unoccupied sites were low, regardless of hydrologic conditions.

\section{Effects of site-level characteristics on metapopulation dynamics}

Although drought-mediated processes influenced occupancy dynamics and persistence of metapopulations, sites with pools that were spring-fed or sufficiently deep to retain water year-round reduced those effects, likely by functioning as refugia (Keppel et al. 2012). Our results are consistent with other studies of amphibian metapopulations in the western United States where persistence depended on sites that held water year-round or at least longer than the time required for tadpoles to reach metamorphosis (Chandler et al. 2015, Ray et al. 2016). Generally, surface-water reliability is a strong predictor of extinction but explains less variation in recolonization rates of unoccupied sites (Chandler et al. 2015, Ray et al. 2016). The distribution of these hydrologic refugia might explain why occupancy of lowland leopard frogs in the southern watershed, where surface water was reliable at more than one-half of sites, did not decrease appreciably when drought conditions were severe. In contrast, occupancy in the northern watershed, where water was reliable at less than one-third of sites, decreased markedly as drought severity increased. Results from our forecasts suggest this decline was likely a function of site characteristics rather than the number 

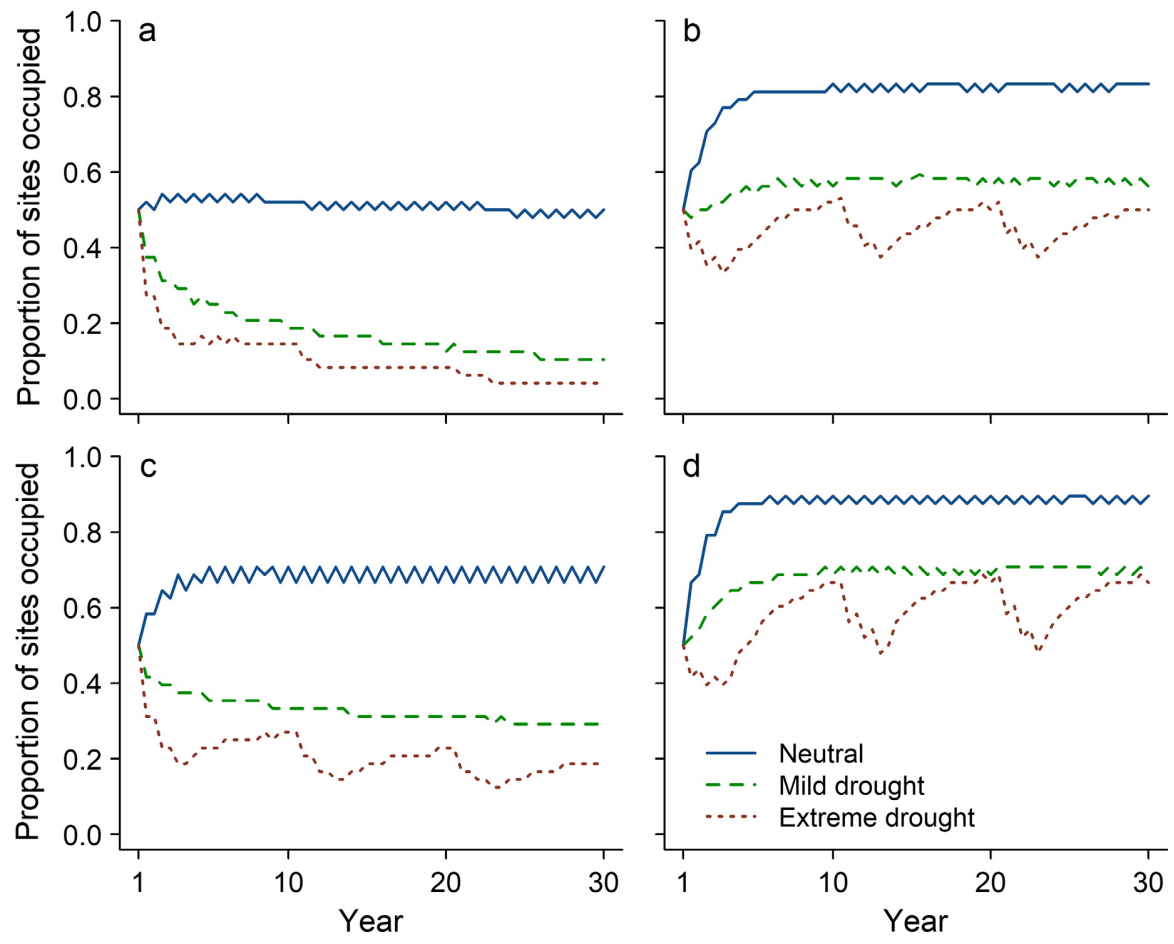

FIG. 7. Proportion of sites occupied over $30 \mathrm{yr}$ in simulated metapopulations of lowland leopard frogs under three climate scenarios: (1) neutral conditions, (2) persistent, mild drought, and (3) extreme three-year droughts occurring once per decade. Metapopulations were characterized by (a) low water reliability and long distances between sites, (b) high water reliability and long distances between sites, (c) low water reliability and short distances between sites, and (d) high water reliability and short distances between sites. Lines represent the medians of posterior distributions. In all simulations, we assumed $50 \%$ of sites were occupied in the first year.

of sites, as even large metapopulations had significant probabilities of extinction when only a small proportion of sites had reliable surface water and when droughts were persistent or severe. Like other amphibians in arid regions, persistence of leopard frogs in the Sky Island region likely depends on refugia with reliable surface water, the quantity and quality of which are likely to decrease with anticipated changes in climate and disturbance regimes (Westerling et al. 2006, Seager et al. 2007, Cook et al. 2015).

Effects of wildfire on amphibian populations have been studied in forest ecosystems (Dunham et al. 2007, Hossack et al. 2013b) but not in deserts. In low-elevation deserts that have not been invaded by nonnative grasses, wildfires are generally rare and low intensity (McLaughlin and Bowers 1982, Brooks and Matchett 2006). Wildfires in these areas are unlikely to cause direct mortality of stream-dwelling species, as fuels in and near stream channels are often insufficient to sustain fire. Standreplacing fires in forests at higher elevations, however, can affect species that inhabit downstream reaches because post-fire erosion often transports large amounts of sediment from the upper watershed to pools below (Parker 2006, Goode et al. 2012). Though increases in sedimentation were not associated with local extinctions of leopard frog populations during our study, frogs were less likely to recolonize sites with moderate to high levels of sediment (average sediment volume $\geq 25 \%$ ). Because sediment levels declined slowly (high levels persisted for an average of $6.2 \mathrm{yr}$ at sites affected by fires in forests at high elevation), affected sites were likely to remain unoccupied for many years following fire. Our study is one of the first to associate amphibian declines with wildfirecaused sedimentation, yet we expect these secondary effects of fire to occur more frequently as the number of severe, large-scale wildfires is expected to increase in the western United States (Westerling et al. 2006, Goode et al. 2012).

Although we found that declines in lowland leopard frogs were associated with drought and the downstream consequences of wildfire, other factors may have influenced their population dynamics. Batrachochytrium dendrobatidis $(\mathrm{Bd})$, a fungal pathogen that causes chytridiomycosis, has been implicated in declines or extinctions of several montane amphibians in the western United States (Bradford 1991, Kagarise Sherman and Morton 1993, Muths et al. 2003). With few exceptions, most amphibian populations in the warmer deserts of the southwestern United States persist with low rates of infection (Schlaepfer et al. 2007, Savage et al. 2011); disease-related mortality, when it occurs, is generally expected in cooler winter months (Forrest and 
Schlaepfer 2011, Savage et al. 2011). Although we did not test for presence of $\mathrm{Bd}$ throughout the study, our analyses suggest that factors other than disease were the primary drivers of the declines we documented, as most local extinction events occurred during summer. We note, however, that extirpation of lowland leopard frogs from a canyon near our study area in 2011 was associated with high rates of Bd infection (Savage et al. 2011).

\section{ConClusions}

As anthropogenic activities decrease the quantity and continuity of habitat for many species, applications for metapopulation theory are likely to increase (Hanski 1999). In most spatially explicit models of metapopulation dynamics, colonization and extinction probabilities are assumed to vary among sites solely as a function of patch area and connectivity, despite evidence indicating that these dynamic processes reflect variation in climate, hydrology, or other environmental factors (Royle and Kéry 2007, Ray et al. 2016). Such constraints are often unavoidable when exploring data collected over relatively short time periods that fail to capture appreciable variation in environmental conditions. In contrast, analysis of data from long-term studies with flexible models that allow for spatial and temporal variation in transition parameters can provide insights into mechanisms that govern distributional dynamics and therefore contribute to conservation of species with patchy distributions. In our case study, for example, results will help managers identify locations to reintroduce lowland leopard frogs, prioritize areas for habitat restoration based on the reliability of surface water, and determine whether populations should be translocated following catastrophic fires or similar landscape-level disturbances. More broadly, our work facilitates development of ecological models that account for potential sources of variation in extinction and colonization rates, that reflect landscape structure and dispersal processes, and that account for imperfect detection during field surveys.

\section{Acknowledgments}

We acknowledge the efforts of many staff and volunteers at Saguaro National Park, especially those who helped collect these long-term survey data. In particular, we thank C. Schwalbe, N. Kline, M. Ward, K. O'Brien, and S. Stonum. We also thank Friends of Saguaro National Park and the Western National Parks Association for supporting these long-term monitoring efforts. B. Beal, P. Brown, and B. Weise helped with recent field surveys. Finally, we thank L. Bailey, D. Christianson, W. Piegorsch, and two anonymous reviewers for insightful comments that improved the manuscript. Some of the funding for this project was provided by the U.S. Geological Survey's Amphibian Research and Monitoring Initiative (ARMI). This manuscript is ARMI contribution no. 682. Any use of trade, product, or firm names is for descriptive purposes only and does not imply endorsement by the U.S. Government.

\section{Literature Cited}

Abatzoglou, J. T., D. J. McEvoy, and K. T. Redmond. 2017. The west wide drought tracker: drought monitoring at fine spatial scales. Bulletin of the American Meteorological Society 98:1815-1820.

Benard, M. F. 2015. Warmer winters reduce frog fecundity and shift breeding phenology, which consequently alters larval development and metamorphic timing. Global Change Biology 21:1058-1065.

Bled, F., J. A. Royle, and E. Cam. 2011. Hierarchical modeling of an invasive spread: the Eurasian Collared-dove Streptopelia decaocto in the United States. Ecological Applications 21:290-302.

Bowers, J. E., and S. P. McLaughlin. 1987. Flora and vegetation of the Rincon Mountains, Pima County, Arizona. Desert Plants 8:51-94.

Bradford, D. F. 1991. Mass mortality and extinction in a highelevation population of Rana muscosa. Journal of Herpetology 25:174-177.

Broms, K. M., M. B. Hooten, D. S. Johnson, R. Altwegg, and L. L. Conquest. 2016. Dynamic occupancy models for explicit colonization processes. Ecology 97:194-204.

Brooks, M. L., and J. R. Matchett. 2006. Spatial and temporal patterns of wildfires in the Mojave Desert, 1980-2004. Journal of Arid Environments 67:148-164.

Brown, D. E. 1982. Biotic communities of the American Southwest-United States and Mexico. Desert Plants 4:1-342.

Cayuela, H., D. Arsovski, E. Bonnaire, R. Duguet, P. Joly, and A. Besnard. 2016. The impact of severe drought on survival, fecundity, and population persistence in an endangered amphibian. Ecosphere 7:e01246.

Chandler, R. B., E. Muths, B. H. Sigafus, C. R. Schwalbe, C. J. Jarchow, and B. R. Hossack. 2015. Spatial occupancy models for predicting metapopulation dynamics and viability following reintroduction. Journal of Applied Ecology 52:13251333.

Chen, I.-C., J. K. Hill, R. Ohlemüller, D. B. Roy, and C. D. Thomas. 2011. Rapid range shifts of species associated with high levels of climate warming. Science 333:1024-1026.

Cook, B. I., T. R. Ault, and J. E. Smerdon. 2015. Unprecedented 21st century drought risk in the American Southwest and Central Plains. Science Advances 1:e1400082.

Daszak, P., D. E. Scott, A. M. Kilpatrick, C. Faggioni, J. W. Gibbons, and D. Porter. 2005. Amphibian population declines at Savannah River Site are linked to climate, not chytridiomycosis. Ecology 86:3232-3237.

Dunham, J. B., A. E. Rosenberger, C. H. Luce, and B. E. Rieman. 2007. Influences of wildfire and channel reorganization on spatial and temporal variation in stream temperature and the distribution of fish and amphibians. Ecosystems 10:335346.

Eaton, M. J., P. T. Hughes, J. E. Hines, and J. D. Nichols. 2014. Testing metapopulation concepts: effects of patch characteristics and neighborhood occupancy on the dynamics of an endangered lagomorph. Oikos 123:662-676.

Ehrlén, J., and W. F. Morris. 2015. Predicting changes in the distribution and abundance of species under environmental change. Ecology Letters 18:303-314.

Ferrari, S., and F. Cribari-Neto. 2004. Beta regression for modelling rates and proportions. Journal of Applied Statistics 31:799-815.

Forrest, M. J., and M. A. Schlaepfer. 2011. Nothing a hot bath won't cure: infection rates of amphibian chytrid fungus correlate negatively with water temperature under natural field settings. PLoS ONE 6:e28444. 
Franken, R. J., and D. S. Hik. 2004. Influence of habitat quality, patch size and connectivity on colonization and extinction dynamics of collared pikas Ochotona collaris. Journal of Animal Ecology 73:889-896.

Gaston, K. J. 2003. The structure and dynamics of geographic ranges. Oxford University Press, Oxford, UK.

Gelman, A., and D. B. Rubin. 1992. Inference from iterative simulation using multiple sequences. Statistical Science 7:457-472.

Goode, J. R., C. H. Luce, and J. M. Buffington. 2012. Enhanced sediment delivery in a changing climate in semi-arid mountain basins: implications for water resource management and aquatic habitat in the northern Rocky Mountains. Geomorphology 139-140:1-15.

Grimm, N. B., and S. G. Fisher. 1992. Responses of arid-land streams to changing climate. Pages $211-233$ in P. Firth and S. G. Fisher, editors. Global climate change and freshwater ecosystems. Springer-Verlag, New York, New York, USA.

Hanski, I. 1999. Metapopulation ecology. Oxford University Press, Oxford, UK.

Hanski, I., A. Moilanen, T. Pakkala, and M. Kuussaari. 1996. The quantitative incidence function model and persistence of an endangered butterfly metapopulation. Conservation Biology 10:578-590.

Harrison, P. J., I. Hanski, and O. Ovaskainen. 2011. Bayesian state-space modeling of metapopulation dynamics in the Glanville fritillary butterfly. Ecological Monographs 81:581598.

Heard, G. W., M. A. McCarthy, M. P. Scroggie, J. B. Baumgartner, and K. M. Parris. 2013. A Bayesian model of metapopulation viability, with application to an endangered amphibian. Diversity and Distributions 19:555-566.

Hodgson, J. A., A. Moilanen, and C. D. Thomas. 2009. Metapopulation responses to patch connectivity and quality are masked by successional habitat dynamics. Ecology 90:1608-1619.

Hossack, B. R., et al. 2013a. Roles of patch characteristics, drought frequency, and restoration in long-term trends of a widespread amphibian. Conservation Biology 27:1410-1420.

Hossack, B. R., W. H. Lowe, and P. S. Corn. 2013b. Rapid increases and time-lagged declines in amphibian occupancy after wildfire. Conservation Biology 27:219-228.

Jaeger, K. L., J. D. Olden, and N. A. Pelland. 2014. Climate change poised to threaten hydrologic connectivity and endemic fishes in dryland streams. Proceedings of the National Academy of Sciences USA 111:13894-13899.

Kagarise Sherman, C., and M. L. Morton. 1993. Population declines of Yosemite toads in the eastern Sierra Nevada of California. Journal of Herpetology 27:186-198.

Kellner, K. 2015. jagsUI: a wrapper around rjags to streamline JAGS analyses. R package version 1.4.4. https://CRAN. R-project.org/package $=$ jagsUI

Keppel, G., K. P. Van Niel, G. W. Wardell-Johnson, C. J. Yates, M. Byrne, L. Mucina, A. G. T. Schut, S. D. Hopper, and S. E. Franklin. 2012. Refugia: identifying and understanding safe havens for biodiversity under climate change. Global Ecology and Biogeography 21:393-404.

Knowlton, J. L., and C. H. Graham. 2010. Using behavioral landscape ecology to predict species' responses to land-use and climate change. Biological Conservation 143:1342-1354.

Levins, R. 1969. Some demographic and genetic consequences of environmental heterogeneity for biological control. Bulletin of the Entomological Society of America 15:237-240.

McLaughlin, S. P., and J. E. Bowers. 1982. Effects of wildfire on a Sonoran Desert plant community. Ecology 63:246-248.

McMenamin, S. K., E. A. Hadly, and C. K. Wright. 2008. Climatic change and wetland desiccation cause amphibian decline in Yellowstone National Park. Proceedings of the National Academy of Sciences USA 105:16988-16993.

Miller, D. A. W., C. S. Brehme, J. E. Hines, J. D. Nichols, and R. N. Fisher. 2012. Joint estimation of habitat dynamics and species interactions: disturbance reduces co-occurrence of non-native predators with an endangered toad. Journal of Animal Ecology 81:1288-1297.

Muths, E., P. S. Corn, A. P. Pessier, and D. E. Green. 2003. Evidence for disease-related amphibian decline in Colorado. Biological Conservation 110:357-365.

Northrup, J. M., and B. D. Gerber. 2018. A comment on priors for Bayesian occupancy models. PLoS ONE 13: e0192819.

O’Brien, T. G., M. F. Kinnaird, A. Nurcahyo, M. Prasetyaningrum, and M. Iqbal. 2003. Fire, demography and the persistence of siamang (Symphalangus syndactylus: Hylobatidae) in a Sumatran rainforest. Animal Conservation 6:115121

Parker, J. T. C. 2006. Post-wildlife sedimentation in Saguaro National Park, Rincon Mountain District, and effects on lowland leopard frog habitat. Scientific Investigations Report 2006-5235. U.S. Geological Survey, Reston, Virginia, USA.

Parmesan, C. N. 2006. Ecological and evolutionary responses to recent climate change. Annual Review of Ecology, Evolution and Systematics 37:636-637.

Parmesan, C., et al. 1999. Poleward shifts in geographical ranges of butterfly species associated with regional warming. Nature 399:579-583.

Pechmann, J. H. K., D. E. Scott, R. D. Semlitsch, J. P. Caldwell, L. J. Vitt, and J. W. Gibbons. 1991. Declining amphibian populations: the problem of separating human impacts from natural fluctuations. Science 253:892-895.

Peterson, E. E., et al. 2013. Modelling dendritic ecological networks in space: an integrated network perspective. Ecology Letters 16:707-719.

Pilliod, D. S., R. S. Arkle, J. M. Robertson, M. A. Murphy, and W. C. Funk. 2015. Effects of changing climate on aquatic habitat and connectivity for remnant populations of a wideranging frog species in an arid landscape. Ecology and Evolution 5:3979-3994.

R Core Team. 2016. R: a language and environment for statistical computing. R Foundation for Statistical Computing, Vienna, Austria. www.R-project.org

Ray, A. M., W. R. Gould, B. R. Hossack, A. J. Sepulveda, D. P. Thoma, D. A. Patla, R. Daley, and R. Al-Chokhachy. 2016. Influence of climate drivers on colonization and extinction dynamics of wetland-dependent species. Ecosphere 7:e01409.

Reading, C. J. 2007. Linking global warming to amphibian declines through its effects on female body condition and survivorship. Oecologia 151:125-131.

Risk, B. B., P. de Valpine, and S. R. Beissinger. 2011. A robustdesign formulation of the incidence function model of metapopulation dynamics applied to two species of rails. Ecology 92:462-474.

Robinson, R. A., S. R. Baillie, and H. Q. P. Crick. 2007. Weather-dependent survival: implications of climate change for passerine population processes. Ibis 149:357-364.

Royle, J. A., and M. Kéry. 2007. A Bayesian state-space formulation of dynamic occupancy models. Ecology 88:1813-1823.

Savage, A. E., M. J. Sredl, and K. R. Zamudio. 2011. Disease dynamics vary spatially and temporally in a North American amphibian. Biological Conservation 144:1910-1915.

Scheele, B. C., D. A. Driscoll, J. Fischer, and D. A. Hunter. 2012. Decline of an endangered amphibian during an extreme climatic event. Ecosphere 3:101.

Schlaepfer, M. A., M. J. Sredl, P. C. Rosen, and M. J. Ryan. 2007. High prevalence of Batrachochytrium dendrobatidis in 
wild populations of lowland leopard frogs Rana yavapaiensis in Arizona. EcoHealth 4:421-427.

Schwarzkopf, L., and R. A. Alford. 2002. Nomadic movement in tropical toads. Oikos 96:492-506.

Seager, R., et al. 2007. Model projections of an imminent transition to a more arid climate in southwestern North America. Science 316:1181-1184.

Spotila, J. R., and E. N. Berman. 1976. Determination of skin resistance and the role of the skin in controlling water loss in amphibians and reptiles. Comparative Biochemistry and Physiology A 55:407-411.

Sredl, M. J. 2005. Rana yavapaiensis. Pages 596-599 in M. Lannoo, editor. Amphibian declines: the conservation status of United States species. University of California Press, Berkeley, California, USA.

Sredl, M. J., J. M. Howland, J. E. Wallace, and L. S. Saylor. 1997. Status and distribution of Arizona's native ranid frogs. Pages 37-89 in M. J. Sredl, editor. Ranid frog conservation and management. Technical report 121. Nongame and Endangered Wildlife Program, Arizona Game and Fish Department, Phoenix, Arizona, USA.

Stewart, J. A. E., D. H. Wright, and K. A. Heckman. 2017. Apparent climate-mediated loss and fragmentation of core habitat of the American pika in the northern Sierra Nevada, California, USA. PLoS ONE 12:e181834.

Sutherland, C. S., D. A. Elston, and X. Lambin. 2014. A demographic, spatially explicit patch occupancy model of metapopulation dynamics and persistence. Ecology 95:3149-3160.

Thomas, C. D., and J. J. Lennon. 1999. Birds extend their ranges northwards. Nature 399:213.

Tingley, R., and R. Shine. 2011. Desiccation risk drives the spatial ecology of an invasive anuran (Rhinella marina) in the Australian semi-desert. PLoS ONE 6:e25979.

Todd, B. D., D. E. Scott, J. H. K. Pechmann, and J. W. Gibbons. 2011. Climate change correlates with rapid delays and advancements in reproductive timing in an amphibian community. Proceedings of the Royal Society B 278:21912197.

Valentine-Darby, P., L. Baril, K. Struthers, C. Filippone, D. Swann, A. Mathis, and N. Chambers. 2017. Saguaro National Park: natural resource condition assessment NPS/SODN/ NRR-2017/1364. National Park Service, Fort Collins, Colorado, USA.

Wallace, J. E., R. J. Steidl, and D. E. Swann. 2010. Habitat characteristics of lowland leopard frogs in mountain canyons of southeastern Arizona. Journal of Wildlife Management 74:808-815.

Werner, E. E., R. A. Relyea, K. L. Yurewicz, D. K. Skelly, and C. J. Davis. 2009. Comparative landscape dynamics of two anuran species: climate-driven interaction of local and regional processes. Ecological Monographs 79:503-521.

Westerling, A. L., H. G. Hidalgo, D. R. Cayan, and T. W. Swetnam. 2006. Warming and earlier spring increase western U.S. forest wildfire activity. Science 313:940-943.

Witte, C. L., M. J. Sredl, A. S. Kane, and L. L. Hungerford. 2008. Epidemiologic analysis of factors associated with local disappearances of native ranid frogs in Arizona. Conservation Biology 22:375-383.

Yackulic, C. B., J. Reid, R. Davis, J. E. Hines, J. D. Nichols, and E. Forsman. 2012. Neighborhood and habitat effects on vital rates: expansion of the Barred Owl in the Oregon Coast Ranges. Ecology 93:1953-1966.

Yackulic, C. B., J. D. Nichols, J. Reid, and R. Der. 2015. To predict the niche, model colonization and extinction. Ecology 96:16-23.

Zylstra, E. R., R. J. Steidl, D. E. Swann, and K. Ratzlaff. 2015. Hydrologic variability governs population dynamics of a vulnerable amphibian in an arid environment. PLoS ONE 10: e0125670.

Zylstra, E. R., D. E. Swann, and R. J. Steidl. 2019. Surfacewater availability governs survival of an amphibian in arid mountain streams. Freshwater Biology 64:164-174.

\section{SUPPORTING INFORMATION}

Additional supporting information may be found online at: http://onlinelibrary.wiley.com/doi/10.1002/eap.1859/full

\section{Data Availability}

Data and code are available on Open Science Framework: https://doi.org/10.17605/osf.io/43pvj 